\title{
Multiphase PMSM and PMaSynRM Flux Map Model with Space Harmonics and Multiple Plane Cross Harmonic Saturation
}

\author{
Tomasz Michalski \\ Electronic Engineering \\ Department \\ Universitat Politècnica de \\ Catalunya \\ Barcelona, Spain \\ tomasz.michalski@upc.edu
}

\author{
Fernando Acosta-Cambranis \\ Electronic Engineering \\ Department \\ Universitat Politècnica de \\ Catalunya \\ Barcelona, Spain \\ fernando.geovany.acosta.cambra \\ @upc.edu
}

\author{
Luis Romeral \\ Electronic Engineering \\ Department \\ Universitat Politècnica de \\ Catalunya \\ Barcelona, Spain \\ luis.romeral@upc.edu
}

\author{
Jordi Zaragoza \\ Electronic Engineering \\ Department \\ Universitat Politècnica de \\ Catalunya \\ Barcelona, Spain \\ jordi.zaragoza- \\ bartomeu@upc.edu
}

\begin{abstract}
Multiphase Synchronous Machines vary in rotor construction and winding distribution leading to non-sinusoidal inductances along the rotor periphery. Moreover, saturation and cross-saturation effects make the precise modeling a complex task. This paper proposes a general model of multi-phase magnetexcited synchronous machines considering multi-dimensional space modeling and revealing cross-harmonic saturation. The models can predict multiphase motor behavior in any transient state, including startup. They are based on flux maps obtained from static 2D Finite-Element (FE) analysis. FE validations have been performed to confirm authenticity of the dynamic models of multiphase PMaSynRMs. Very close to FE precision is guaranteed while computation time is incomparably lower.
\end{abstract}

Keywords- Permanent Magnet Machines (PMSM), Synchronous Reluctance Machines (SRM), Finite Element Analysis (FEM), machine modeling, cross harmonic saturation, space harmonics, multiphase machines.

\section{INTRODUCTION}

Permanent magnet synchronous machines (PMSMs) have become extremely important in the industry because they offer very high efficiency and torque density [1]. Due to these features they are applied in various electromechanical conversion systems, such as industrial drives, renewable energy (RE) power generation, hybrid and electric vehicles (HEVs), household appliances and other propulsion systems [2], [3].

Furthermore, multiphase PMSMs have gained a lot of interest due to their inherent power division between multiple phases. They find applications where high power and reliability is demanded, such as in aerospace or ship propulsion [4]. Another attractive aspect of multi-phase systems is their fault tolerant operation [5].

PMSMs of three and more phases are divided into surface mounted (SPMSM) and interior (IPMSM) types. The first one exhibits electromagnetic alignment torque whereas the second attributes for the extra reluctance torque component due to magnetic asymmetry in the rotor construction. In the context of this classification, Permanent Magnet assisted Synchronous Reluctance Machines (PMaSynRM) can also be considered as a part of the PMSM family, with the main reluctance torque due to rotor anisotropy and an auxiliary torque, a result of magnets installed onto the rotor magnetic paths. Consistently, saturation phenomena exist in all of these types of machines. Moreover, there is an evident distinction between sinusoidal and concentrated winding machines. The latter ones contain more spatial harmonics, but the discrete sinusoidal distribution also has an impact on the inductance fluctuation, which for the sake of precise modeling should not be disregarded.

Analytical models of PMSM machines have been thoroughly studied by the scientific community to obtain reliable and precise behavior of the electric drives and generators for investigation, design optimization [6], diagnosis [7], control [8], [9], and sensorless observing purposes [10], [11]. Finite Element Analysis (FEA) is widely adopted for the geometrical optimization and performance prediction. While it requires a high computational burden, other rapid and accurate models are sought. To some extent Magnetic Equivalent Circuits (MECs) are interesting options [12]-[14], but mostly for simple rotor structures [15]. Variable inductance estimator was presented in [16], where parameters depend on current magnitude and phase angle, and are extracted from the stored energy using FEA model and motor steady state operation. Modified two-axis model was proposed in [17], in which self and cross-coupling inductances were introduced and experimentally evaluated in locked rotor condition. However, these methods do not take into account the significant amount of space harmonics present due to slotting and local saturations. Their existence was filtered in [18], but still it led only to the fundamental inductance components with cross saturations. The model from [17] was extended in [19] to include current and position dependent characteristics of the flux linkages assuming 


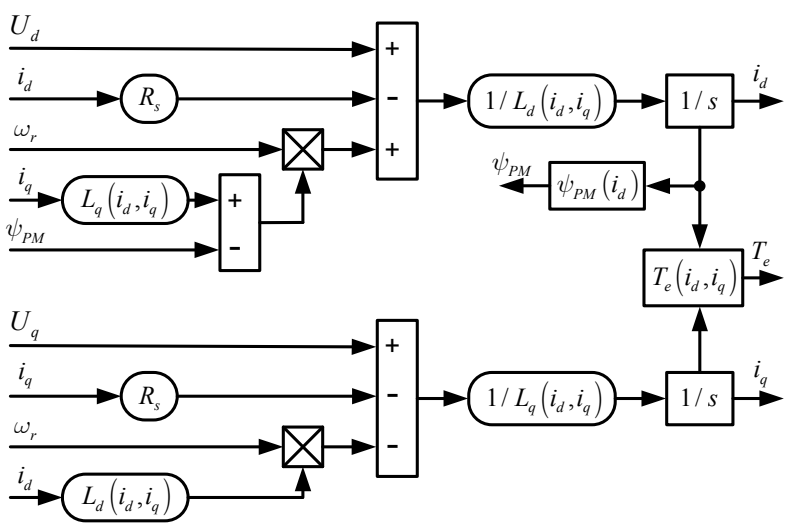

Fig. 1. PMaSynRM classic model (PMaSynRM dq convention)

permanent magnet flux as only position dependent. In spite of this simplification, the model gave very good matching with the FEA. A detailed model with iron losses included for the time stepping simulation based on the inverse solution of fluxes was proposed in [20]. It works on flux linkages and does not separate flux from permanent magnet on the grounds that the superposition principle does not hold under saturation conditions. The model contains two current maps and one torque map. Similar concept had been proposed in [21] (and [22] for natural $a b c$ system). Nonetheless the initial condition of the $d q$ fluxes is not taken into account and is limited to three phases only (one $d q$ plane).

This work proposes generalized detailed model of PMSM (PMa-SynRM) multiphase machines with any kind of rotor construction and unrestricted number of phases with start dynamics. The model extends standard two axis inverted flux maps approach to multiphase multiplane. Maps can be identified by 2 D static FEA. Since the fluxes in multiple $d q$ frames depend on multiple $d$ and $q$ currents and also rotor position, the model comprises discrete winding distribution, slotting and iron saturation. It is recognized that the permeability of iron is affected by the currents from $d q 3$ plane as well (and other higher order planes if exist), creating plane cross saturation effects. These specific multiphase electric machinery features combined with the non-sinusoidal currents imposed by the power electronic converters give origin of higher harmonics in machine magneto-motive forces (MMFs) and fluxes so eventually in the developed torque. Transformations used in this work are in compliance with apparatus of multiple $d q$ spaces [23], [24].

The startup condition is included for every plane. It depends on the flux from permanent magnets which in turn is modulated by the rotor position. This means that another map is necessary for the motor startup modeling.

FEA verification of the novel model was carried out on the five phase PMA-SynRM without loss of generality. For higher number of phases more planes can be added, although with computation tradeoff. A convention of reluctance machines, with $d l$ axis fixed to the highest permeance and $q 1$ axis orthogonal to it, is used to denominate $d q 1$ plane.

The proposed model allows FEA accurate, fast simulations and analysis from the startup transient of any PMSM family motor behavior with no phase number restriction for high
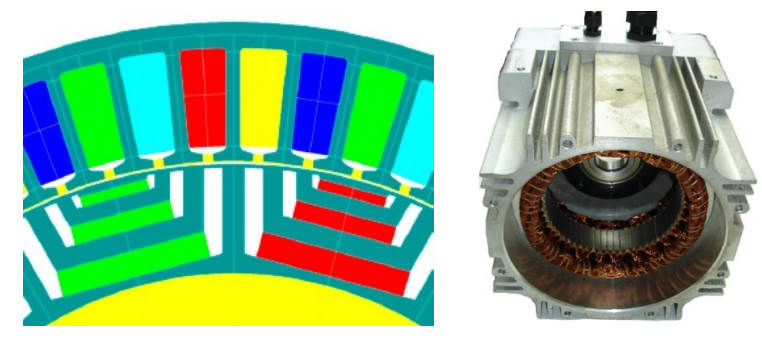

Fig. 2. Cross section and stator of the five-phase PMaSynRM prototype

TABLE I

PROTOTYPE MACHINE SPECIFICATION

\begin{tabular}{ccc}
\hline \hline Quantity & Unit & Value \\
\hline Number of phases & - & 5 \\
Rated torque & $\mathrm{Nm}$ & 6.8 \\
Base speed & $\mathrm{r} / \mathrm{min}$ & 5000 \\
Rated power & $\mathrm{kW}$ & 3.5 \\
Peak current & $\mathrm{A}$ & 12 \\
Rated current & $\mathrm{A}$ & 4.5 \\
Stator resistance & $\Omega$ & 2.2 \\
Number of pole pairs & - & 6 \\
Number of slots & - & 60 \\
Active stack length & $\mathrm{mm}$ & 26 \\
Stator outer diameter & $\mathrm{mm}$ & 148 \\
Rotor outer diameter & $\mathrm{mm}$ & 114 \\
Airgap length & $\mathrm{mm}$ & 6 \\
Number of skew sections & - & 2 \\
Skew angle & $\circ$ & 6 \\
\hline \hline
\end{tabular}

performance drives. They can be implemented in hardware in the loop test benches and used for drive evaluation.

\section{CONVENTIONAL PMASYNRM MODEL}

The conventional $d q$ model for three-phase machines is well known in the literature and it assumes infinite iron permeability, sinusoidal flux distribution, and therefore constant parameters. Variable inductances are directly projected on this model (Fig. 1) to include magnetic saturation:

$$
\begin{gathered}
U_{d}=R_{s} i_{d}+L_{d} \frac{d i_{d}}{d t}-\omega_{r}\left(L_{q} i_{q}-\psi_{P M}\right) \\
U_{q}=R_{s} i_{q}+L_{q} \frac{d i_{q}}{d t}+\omega_{r} L_{d} i_{d} \\
L_{d}=f_{1}\left(i_{d}, i_{q}\right), L_{q}=f_{2}\left(i_{d}, i_{q}\right), \psi_{P M}=f_{3}\left(i_{d}\right) \\
T_{e}=\frac{m}{2} p\left(\psi_{P M} i_{q}+\left(L_{d}-L_{q}\right) i_{d} i_{q}\right)
\end{gathered}
$$

where the $d q$ inductances and permanent magnet flux linkage $\psi_{P M}$ are functions of currents.

Since this model is simplified it cannot predict motor behavior under startup and dynamic conditions. The inductances depend sinusoidally on the rotor position (fundamental component) and become constant ("DC signals") after ClarkePark transform. However, with the space harmonics included these inductances become distorted. Also, time derivative of the 


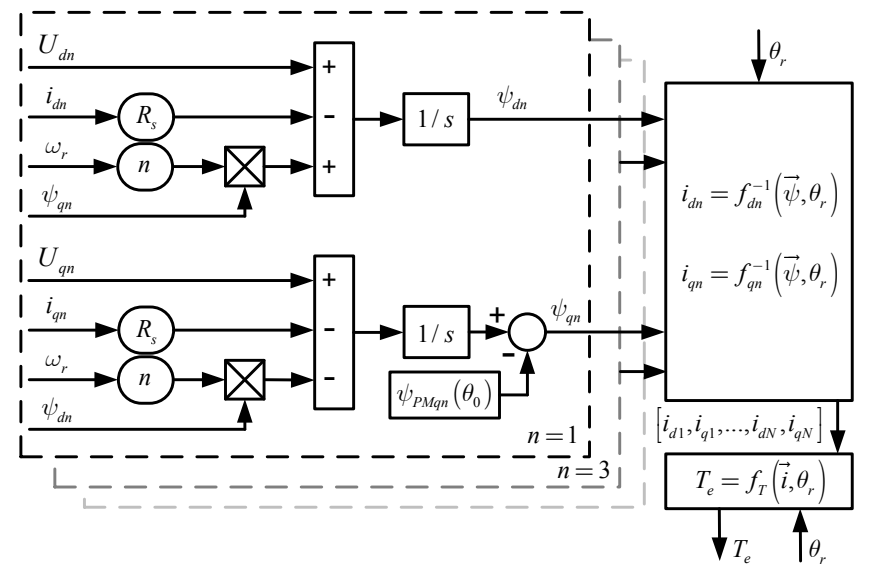

Fig. 3. Proposed multiphase PMSM dynamic model based on inverted flux maps (current maps)

PM flux is omitted. Eventually it is valid for three phases only as $d q 3$ and other planes do not exist. It has been recognized that especially under saturation this model is inaccurate and particularly disadvantageous for maximum torque per ampere (MTPA) control strategy [20-22].

\section{NONLINEAR MULTIPHASE PMASYNRM MODEL}

To overcome the aforementioned problems with the conventional model, a reliable electromagnetic model is presented in this section. It is elaborated on a five-phase 60-slot, 6-pole PMaSynRM prototype machine with parameters specified in Table I and the cross section shown in Fig. 2. The model can be extended to any configuration of PMSM motors.

Instead of using inductances and permanent magnet flux it is possible to operate on the flux linkages only, considering $d q$ and higher order planes (e.g. $d q 3$ in 5-phase system) resulting in set of $N$ equations:

$$
\begin{gathered}
U_{d n}=R_{s} i_{d n}+\frac{d \psi_{d n}}{d t}-n \omega_{r} \psi_{q n} \\
U_{q n}=R_{s} i_{q n}+\frac{d \psi_{q n}}{d t}+n \omega_{r} \psi_{d n} \\
\psi_{d n}=f_{d n}\left(i_{d 1}, i_{q 1}, i_{d 3}, i_{q 3}, \ldots, i_{d N}, i_{q N}, \theta_{r}\right) \\
\psi_{q n}=f_{q n}\left(i_{d 1}, i_{q 1}, i_{d 3}, i_{q 3}, \ldots, i_{d N}, i_{q N}, \theta_{r}\right) \\
T_{e n}=\frac{m}{2} p\left(\psi_{d n} i_{q n}-\psi_{q n} i_{d n}\right) \\
T_{e}=T_{e 1}+T_{e 3}+\ldots+T_{e N}
\end{gathered}
$$

where the $d n, q n$ axis flux linkages $\psi_{d n}, \psi_{q n}$ are functions of all planes $d q$ axes currents and the rotor position $\theta_{r}$ as well (5). Therefore, the nonlinear effects of cross harmonic saturations and space harmonics are included in the flux linkage functions. These functions (5) are identified via FEM analysis performing multi-static currents and rotor position sweep covering all operating conditions. In case of the prototype machine the ranges for $i_{d 1}, i_{q 1}$ are of $\langle-10,10\rangle \mathrm{A}$, for $i_{d 3}, i_{q 3}$ are of $\langle-3,3\rangle$ A and for $\theta_{r}$ is of $\left\langle 0^{\circ}, 60^{\circ}\right\rangle$ (in mechanical degrees). If only one plane was considered, because of the cyclic stator teething and integer slot winding of the prototype machine, the $\theta_{r}$ interval could be reduced. Due to low amplitude of $d q 3$ magnitudes the range for this plane is significantly lower, this is advantageous in terms of reduced dataset. The resolution of the coordinate vectors depends on the step size and the number of FEM steps increases exponentially with higher resolution. Therefore, a reasonably high value of the coordinate step is preferable and the output maps can be post-processed with offline spline divisions. The resulting 5D maps can be elaborated as lookup tables (LUTs) or fitted to function of five variables.

When there is no current excitation, the torque computed by (7) results in null so the variation of magnetic co-energy is not taken into account and therefore the cogging torque is omitted. Nevertheless, the co-energy can be calculated as integrals over the positive current span or obtained from FEM:

$$
\begin{gathered}
W_{d q n}^{\prime}=\int_{i_{d n \min }}^{i_{d n \max }} \psi_{d n}\left(i_{d 1}, i_{q 1}, \ldots, i_{d N}, i_{q N}, \theta_{r}\right) d i_{d n}+ \\
+\int_{i_{q n \max }}^{i_{q n \min }} \psi_{q n}\left(i_{d 1}, i_{q 1}, \ldots, i_{d N}, i_{q N}, \theta_{r}\right) d i_{q n} \\
T=\frac{\partial W_{d q 1}^{\prime}}{\partial \theta_{r}}+\frac{\partial W_{d q 3}^{\prime}}{\partial \theta_{r}}+\ldots+\frac{\partial W_{d q N}^{\prime}}{\partial \theta_{r}}
\end{gathered}
$$

Finally, torque may be calculated from the co-energy gradient (9). However, for the sake of numerical precision full torque can be directly extracted from FEM and written similarly to flux linkages as a function of $d q 1, d q 3$ (and higher) axes currents and rotor position $\theta_{r}$ and it can also be stored in a LUT.

$$
T_{e}=f_{T}\left(i_{d 1}, i_{q 1}, i_{d 3}, i_{q 3}, \ldots, i_{d N}, i_{q N}, \theta_{r}\right)
$$

The flux linkages from all $d q$ planes are calculated by integrals resulting from the voltage model (4) and (5)

$$
\begin{aligned}
& \psi_{d n}=\int\left(U_{d n}-R_{s} i_{d n}+n \omega_{r} \psi_{q n}\right) \\
& \psi_{q n}=\int\left(U_{q n}-R_{s} i_{q n}-n \omega_{r} \psi_{d n}\right)+\psi_{P M q n}\left(\theta_{0}\right)
\end{aligned}
$$

where $n$ subscript denotes one of the existing $d q$ planes reference and $n \in\langle 1,3, \ldots, N\rangle$. It should be noted with regards to the startup modeling, that it is necessary for these integrals to be supplied with the initial condition. This in turn comes from the flux crossing the airgap thrown by the permanent magnets, 


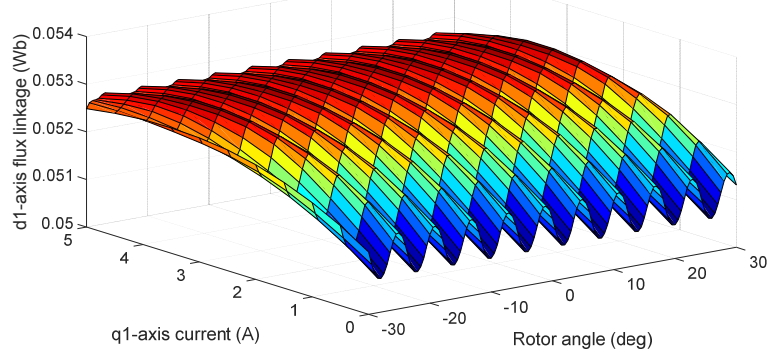

(a)

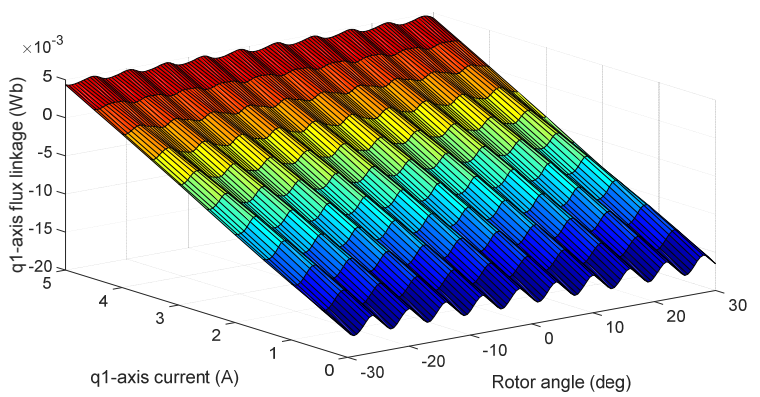

(b)

Fig. 4. d1-axis (a) and $q 1$-axis (b) flux linkage map versus $q 1$ axis current and rotor position for $i_{d l}=5 \mathrm{~A}, i_{d 3}=i_{q 3}=0 \mathrm{~A}$.

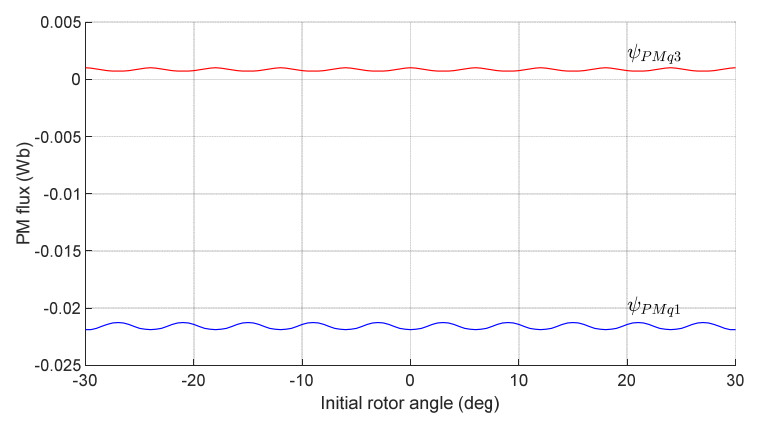

Fig. 5. Flux startup condition for $q 1$ and $q 3$ axes

which obviously depends on the rotor position $\theta_{r}$. It is clear that this information is already obtained by (5) such that:

$$
\psi_{P M q n}\left(\theta_{0}\right)=\psi_{q n}\left(0,0, \ldots, 0, \theta_{0}\right)
$$

However, to determine all $d q$ currents from all $d q$ flux linkages the inverse functions of those in (5) are needed:

$$
\begin{aligned}
& i_{d n}=f_{d n}^{-1}\left(\psi_{d 1}, \psi_{q 1}, \psi_{d 3}, \psi_{q 3}, \ldots, \psi_{d N}, \psi_{q N}, \theta_{r}\right) \\
& i_{q n}=f_{q n}^{-1}\left(\psi_{d 1}, \psi_{q 1}, \psi_{d 3}, \psi_{q 3}, \ldots, \psi_{d N}, \psi_{q N}, \theta_{r}\right)
\end{aligned}
$$

In general, it is a very difficult (N-1)D (because every rotor angle can be treated separately) inverse problem to solve. It can

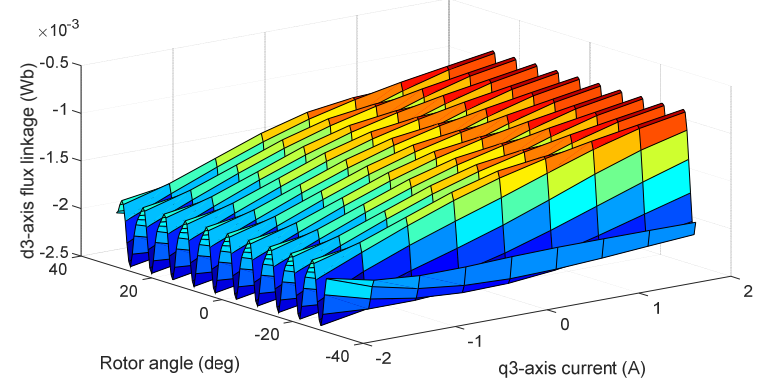

(a)

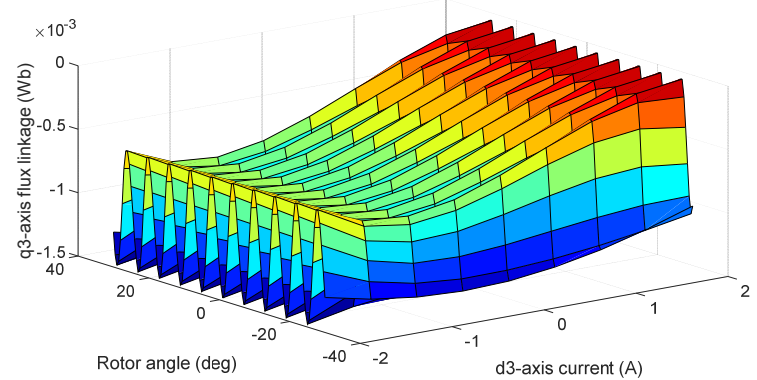

(b)

Fig. 6. $d 3$ axis (a) and $q 3$ axis (b) flux linkage maps versus $q 3$ (a) and $d 3$ (b) axis current and rotor position for $i_{d l}=0.5 \mathrm{~A}, i_{q 1}=4.5 \mathrm{~A}$

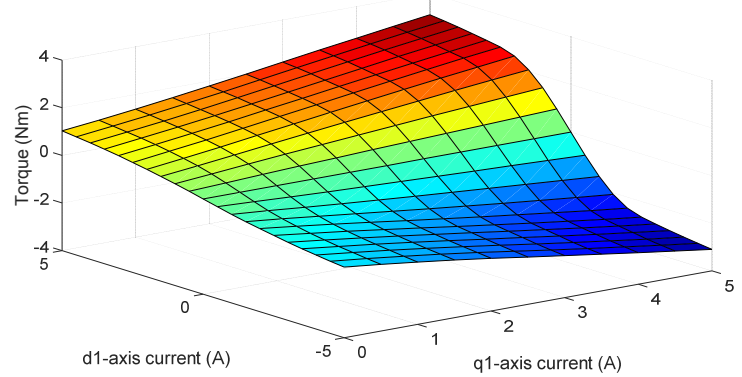

Fig. 7. Electromagnetic torque map versus $d 1$ and $q 1$ axis currents for $i d 3=0 A$, iq $3=0 A$

be accomplished for the complete span of the flux linkages in all $d q$ axes for every rotor position by iterative process that seeks minimum error between a seed and the interpolated map value [20]. This operation, to establish current maps, takes several hours on a mid-class PC station (for case of five phases). The method of inversed grid intersections [22] is also applicable here.

The model schematic is shown in Fig. 3. It is based on (4) and (5). The flux linkages are calculated with (11), the currents and the torque are obtained from functions/maps of (13) and (10) respectively. The flux (5) map variations with respect to one axis current and mechanical angle are shown on Fig. 4 for $d 1$ and $q 1$ axes and in Fig. 6 for $d q 3$ plane. Torque (10) map sub-plane is depicted in Fig. 7. The initial condition from permanent magnets with no current excitation is explicitly shown in Fig. 3 and is computed from the function/map of (12) illustrated in Fig. 5. 


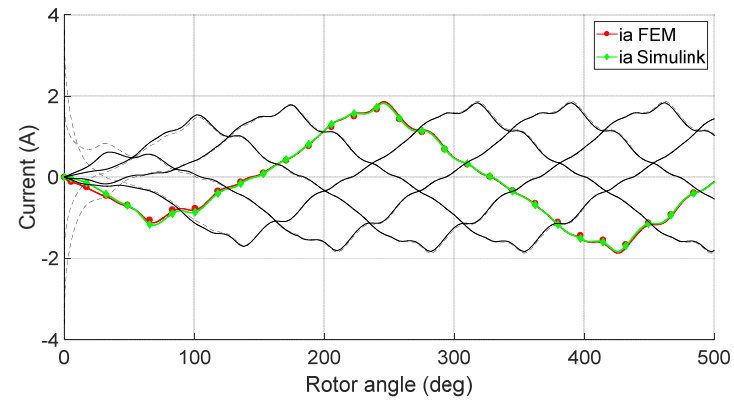

Fig. 8. Electromagnetic torque waveform comparison between Simulink and FEM models.

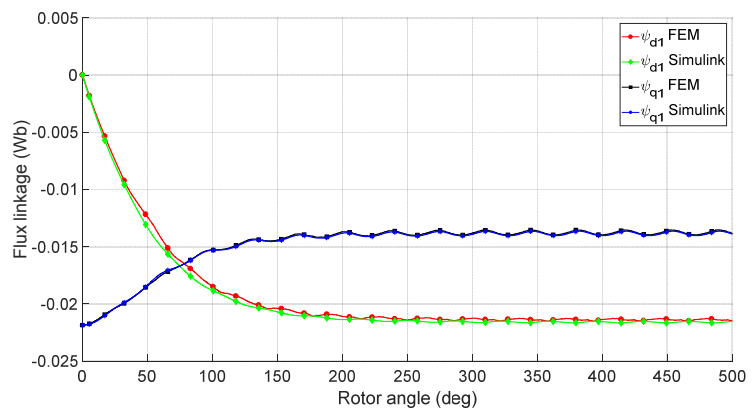

(a)

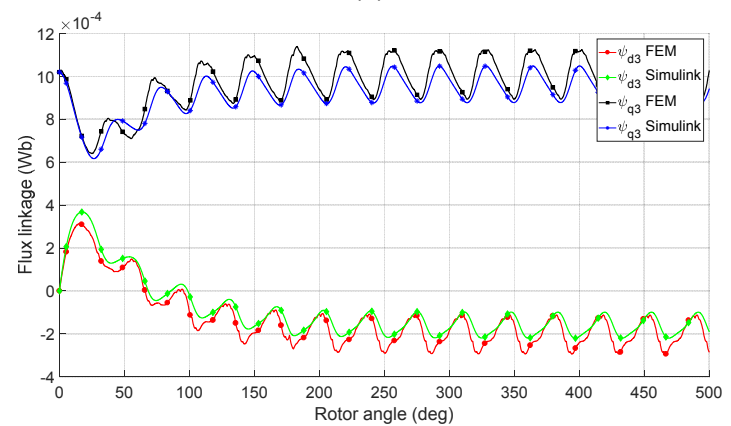

(b)

Fig. 9. $d q 1$ (a) and $d q 3$ (b) flux linkages waveforms comparison between Simulink and FEM models.

Altogether one 2D and five 5D maps are required to run the five phase model.

\section{MODEL VALIDATION}

To corroborate proposed model, a comparison with FEM and validation was performed.

First, the models were evaluated in Matlab 2018a Simulink (block oriented) and Simscape (physical system oriented) environments in dynamic short circuit conditions. FEM validation was made with one $2 \mathrm{D}$ geometry in order to make it simpler and faster; furthermore, not all packages allow simulations of discrete skew machines in multi-slice mode. Complete dataset of maps was previously extracted using Altair Flux 12.3 FEA software on the professional portable personal computer based on 8 core Core i7-3740QM CPU and equipped with 32 GB of RAM memory. FEM model problem solving, result post-processing, and data export for the studied case of multiplane maps takes about 38 hours. Then, in simulation, the

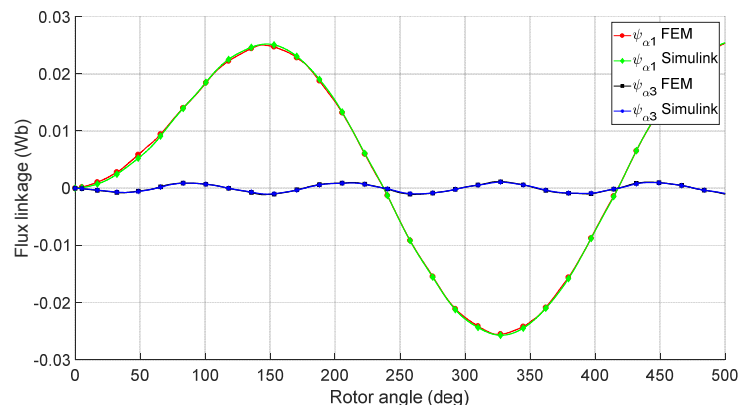

(a)

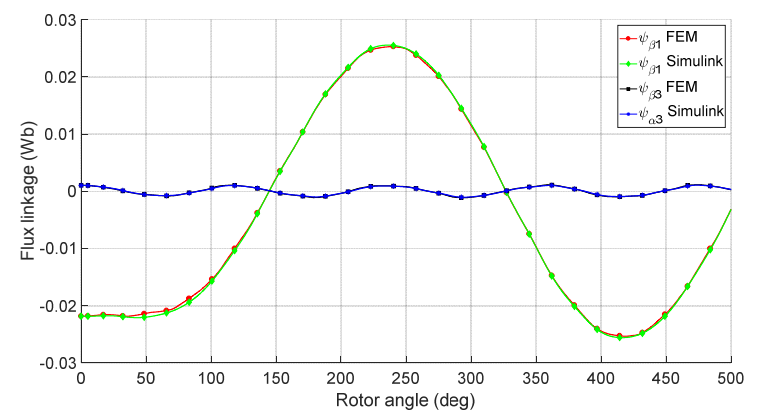

(b)

Fig. 10. $\alpha 1, \alpha 3$ (a) and $\beta 1, \beta 3$ (b) flux linkages waveforms comparison between Simulink and FEM models.

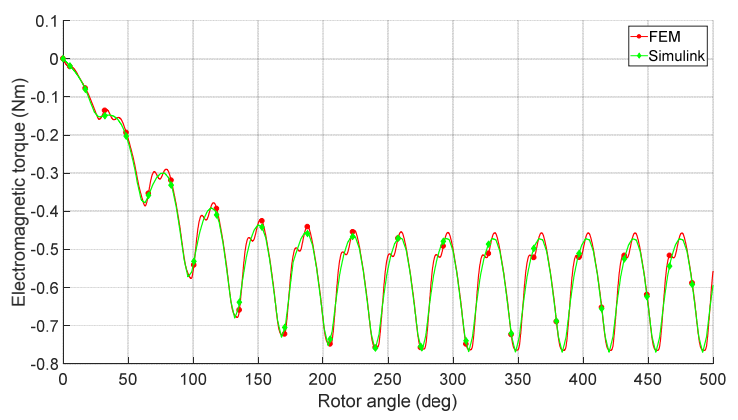

Fig. 11. Electromagnetic torque waveform comparison between Simulink and FEM models.

motor was accelerated from standstill to $200 \mathrm{rpms}$ to catch the initial condition, transient response and the steady state fluctuations of currents (Fig. 8.), fluxes in rotating (Fig. 9.) and stationary (Fig. 10.) reference frames and electromagnetic torque (Fig. 11.). The comparisons are made with 2D FEM with the same scenario. Close matching can be observed for the multi-plane fluxes with their space and slotting effects easily observable. Electromagnetic torque oscillation is very well reflected by the Simulink model and currents are virtually the same. Therefore, the proposed modeling established by the multi-plane space and saturation harmonics is validated by means of FEM simulations on 2D motor. Slight deviations are observable due to step size and interpolations. They can be reduced with higher resolutions of the map extraction.

\section{CONCLUSION}

The equivalent and detailed electromagnetic model of multiphase synchronous machine was described on five-phase 
PMaSynRM example. The model includes not only the classical cross-coupling but also traverse coupling of higher harmonic planes together with space harmonics and initial conditions. Non-sinusoidal winding distribution and cogging torque is also taken into account. Validation by FEA has been performed. The model forms a great tool for multi-phase machines study, evaluation and robust control system development.

\section{ACKNOWLEDGMENT}

This work was supported in part by Spanish Ministry of Economy and Competitiveness under TRA2016-80472-R Research Project and Secretaria d'Universitats i Recerca del Departament d'Empresa i Coneixement de la Generalitat de Catalunya.

\section{REFERENCES}

[1] P. Pillay and R. Krishnan, "Modeling, simulation, and analysis of permanent-magnet motor drives. I. The permanent-magnet synchronous motor drive," IEEE Transactions on Industry Applications, vol. 25, no. 2, pp. 265-273, 1989.

[2] G. Pellegrino, A. Vagati, P. Guglielmi, and B. Boazzo, "Performance Comparison Between Surface-Mounted and Interior PM Motor Drives for Electric Vehicle Application," IEEE Transactions on Industrial Electronics, vol. 59, no. 2, pp. 803-811, 2012.

[3] G. A. Capolino and A. Cavagnino, "New trends in electrical machines technology - Part I," IEEE Transactions on Industrial Electronics, vol. 61, no. 8, pp. 4281-4285, 2014.

[4] L. Parsa and H. A. Toliyat, "Five-phase permanent-magnet motor drives," IEEE Transactions on Industry Applications, vol. 41, no. 1, pp. 30-37, 2005.

[5] Z. Liu, Z. Zheng, and Y. Li, "Enhancing Fault-Tolerant Ability of a NinePhase Induction Motor Drive System Using Fuzzy Logic Current Controllers," IEEE Transactions on Energy Conversion, vol. 32, no. 2, pp. 759-769, 2017.

[6] C. López-Torres, A. Garcia, J. Riba, G. Lux, and L. Romeral, "Computationally Efficient Design and Optimization Approach of PMaSynRM in Frequent Operating Torque-Speed Range," IEEE Transactions on Energy Conversion, vol. 33, no. 4, pp. 1776-1786, 2018.

[7] L. Romeral, J. C. Urresty, J. R. R. Ruiz, and A. G. Espinosa, "Modeling of Surface-Mounted Permanent Magnet Synchronous Motors With Stator Winding Interturn Faults," IEEE Transactions on Industrial Electronics, vol. 58, no. 5, pp. 1576-1585, 2011.

[8] Q. Chen, G. Liu, W. Zhao, L. Qu, and G. Xu, "Asymmetrical SVPWM Fault-Tolerant Control of Five-Phase PM Brushless Motors," IEEE Transactions on Energy Conversion, vol. 32, no. 1, pp. 12-22, 2017.

[9] L. Zhang, Y. Fan, C. Li, A. Nied, and M. Cheng, "Fault-Tolerant Sensorless Control of a Five-Phase FTFSCW-IPM Motor Based on a Wide-Speed Strong-Robustness Sliding Mode Observer," IEEE Transactions on Energy Conversion, vol. 33, no. 1, pp. 87-95, 2018.

[10] S. Bolognani, L. Ortombina, F. Tinazzi, and M. Zigliotto, "Model Sensitivity of Fundamental-Frequency-Based Position Estimators for
Sensorless PM and Reluctance Synchronous Motor Drives," IEEE Transactions on Industrial Electronics, vol. 65, no. 1, pp. 77-85, 2018.

[11] T. Michalski, C. Lopez, A. Garcia, and L. Romeral, "Sensorless control of five phase PMSM based on extended Kalman filter," in IECON 2016 42nd Annual Conference of the IEEE Industrial Electronics Society, 2016, pp. 2904-2909.

[12] S. D. Sudhoff, B. T. Kuhn, K. A. Corzine, and B. T. Branecky, "Magnetic Equivalent Circuit Modeling of Induction Motors," IEEE Transactions on Energy Conversion, vol. 22, no. 2, pp. 259-270, 2007.

[13] N. Bracikowski, M. Hecquet, P. Brochet, and S. V. Shirinskii, "Multiphysics Modeling of a Permanent Magnet Synchronous Machine by Using Lumped Models," IEEE Transactions on Industrial Electronics, vol. 59, no. 6, pp. 2426-2437, 2012.

[14] M. Amrhein and P. T. Krein, "3-D Magnetic Equivalent Circuit Framework for Modeling Electromechanical Devices," IEEE Transactions on Energy Conversion, vol. 24, no. 2, pp. 397-405, 2009.

[15] T. Michalski, C. Lopez, A. Garcia, and L. Romeral, "Dynamic nonlinear reluctance network analysis of five phase outer rotor BLDC machine," in IECON 2016 - 42nd Annual Conference of the IEEE Industrial Electronics Society, 2016, pp. 1790-1795.

[16] K. Gyu-Hong, H. Jung-Pyo, K. Gyu-Tak, and P. Jung-Woo, "Improved parameter modeling of interior permanent magnet synchronous motor based on finite element analysis," IEEE Transactions on Magnetics, vol. 36, no. 4, pp. 1867-1870, 2000.

[17] B. Stumberger, G. Stumberger, D. Dolinar, A. Hamler, and M. Trlep, "Evaluation of saturation and cross-magnetization effects in interior permanent-magnet synchronous motor," IEEE Transactions on Industry Applications, vol. 39, no. 5, pp. 1264-1271, 2003.

[18] K. M. Rahman and S. Hiti, "Identification of machine parameters of a synchronous motor," IEEE Transactions on Industry Applications, vol. 41, no. 2, pp. 557-565, 2005.

[19] M. Hadžiselimović, G. Štumberger, B. Štumberger, and I. Zagradišnik, "Magnetically nonlinear dynamic model of synchronous motor with permanent magnets," Journal of Magnetism and Magnetic Materials, vol. 316, no. 2, pp. e257-e260, 2007.

[20] X. Chen, J. Wang, B. Sen, P. Lazari, and T. Sun, "A High-Fidelity and Computationally Efficient Model for Interior Permanent-Magnet Machines Considering the Magnetic Saturation, Spatial Harmonics, and Iron Loss Effect," IEEE Transactions on Industrial Electronics, vol. 62, no. 7, pp. 4044-4055, 2015.

[21] M. Boesing, M. Niessen, T. Lange, and R. D. Doncker, "Modeling spatial harmonics and switching frequencies in PM synchronous machines and their electromagnetic forces," in 2012 XXth International Conference on Electrical Machines, 2012, pp. 3001-3007.

[22] L. Quéval and H. Ohsaki, "Nonlinear abc-Model for Electrical Machines Using <italic $>\mathrm{N}<$ /italic $>$-D Lookup Tables," IEEE Transactions on Energy Conversion, vol. 30, no. 1, pp. 316-322, 2015.

[23] R. Hyung-Min, K. Jang-Hwan, and S. Seung-Ki, "Analysis of multiphase space vector pulse-width modulation based on multiple d-q spaces concept," IEEE Transactions on Power Electronics, vol. 20, no. 6, pp. 1364-1371, 2005.

[24] E. Levi, "Multiphase Electric Machines for Variable-Speed Applications," IEEE Transactions on Industrial Electronics, vol. 55, no. 5, pp. 1893-1909, 2008. 